\section{THU0175 ASSESMENT OF INSULIN RESISTANCE IN A RHEUMATOID ARTHRITIS INCEPTION COHORT: NESTED CASE-CONTROL STUDY}

S. Manrique-Arija ${ }^{1}$, N. Mena-Vázquez ${ }^{1}$, I. Ureña-Garnica ${ }^{1}$, S. Abad-Sanchez ${ }^{2}$, L. Ginel ${ }^{2}$, C. Fuego-Varela ${ }^{1}$, M. Rojas-Gimenez ${ }^{1}$, L. Cano-Garcia ${ }^{1}$, F.G. JimenezNuñez ${ }^{1}$, G. Diaz-Cordoves ${ }^{1}$, M.C. Ordoñez-Cañizares ${ }^{1}$, C.M. Romero-Barco ${ }^{1}$, R. Caparrós ${ }^{1}$, M.V. Irigoyen ${ }^{1}$, A. Fernandez-Nebro ${ }^{3} .{ }^{1}$ UGC de Reumatología, Instituto de Investigación Biomédica de Málaga(IBIMA), Hospital Regional Universitario de Málaga, Universidad de Málaga; ${ }^{2}$ Health Center Ciudad Jardin (HRUM); ${ }^{3}$ UGC de Reumatología, Instituto de Investigación Biomédica de Málaga (IBIMA), Hospital Regional Universitario de Málaga, Departamento de Medicina y Dermatología, Universidad de Málaga, Malaga, Spain

Objectives: To asses insulin resistance (IR) in patients with rheumatoid arthritis (RA) and compare it with healthy controls and to analyse the association between the accumulated inflammatory burden in patients with RA and IR

Methods_: Design: Nested case-control study. Population: consecutive RApatients (ACR/EULAR 2010 criteria),>16 years, selected from a prospective inception cohort (diagnosis of RA between 2007 and 2011). Patients with Diabetes Mellitus (according to ADA 2010 criteria) were excluded. Controls: sex- age and BMI -matched controls were collected from a health centre in our hospital area. Protocol: Cases and controls were evaluated by a rheumatologist. Clinical data of disease activity (RA patients), analytical values and oral glucose tolerance test (OGTT) were determined. Main outcome: IR measured by the homeostasis model for insulin resistance (HOMA-IR) (IR $\left.>2.29 \mu \mathrm{U}^{*} \mathrm{mmol} / \mathrm{ml}\right)$. Secondary outcome: RI measured by quantitative insulin sensitivity check index (QUICKI) $\left(<0.337 \mu \mathrm{U}{ }^{*} \mathrm{mmol} / \mathrm{ml}\right)$ and by the homeostatic model assessment of $\beta$-cell function (HOMA B).Variables: Demographic, clinical-analytical variables, Disease Activity Score of 28 joints (DAS28-ESR), Health Assessment Questionnaire (HAQ), BMI (OMS classification) and glucose and insulin before and after OGTT values. Statistical analysis: Descriptive and paired T-test or Chi-square test followed by Multivariate linear regression in RA patients (Dependent variable: HOMA-IR)

Results: One hundred and fifty six subjects were studied, 4 of them were excluded after OGTT(2 diabetics and their respective controls). Finally, 1522 subjectswer included; 89 RA and 63 controls. The mean age of patients with RA was $56.6(10.9 \%)$ years. Most of them were women(76.4\%), with seropositive(FR $83.1 \%$ y ACPA $79.1 \%$ ) and erosive (62\%) RA. The mean duration of the disease was $86( \pm 23)$ months and mean DAS28 index at the cut-off date of $2.8( \pm 1.1)$. Differences between clinical characteristics and in relation to IR between cases and controls are shown in table 1. No significant differences in the proportion of subject with IR in cases and controls were observed and $28.7 \%$ of patients with RA had IR. Of the 25 patients with IR, $75 \%$ had an average of DAS $28 \geq 3.2$. In multivariate analysis, the independent variables associated with IR in patients with RA were: Obesity $(\beta=1.7494[p=0.003])$, diagnosis delay $(\beta=0.034[p=0.003])$ and disease activity $(\beta=1.045[p=0.058])$. This model would explain $23 \%$ of the variability of the $\operatorname{IR}\left(R^{2}=0.23\right)$.

\begin{tabular}{lccc}
\hline \multicolumn{1}{c}{ VARIABLE } & $\begin{array}{c}\text { CASES } \\
\mathrm{n}=89\end{array}$ & $\begin{array}{c}\text { CONTROLS } \\
\mathrm{n}=63\end{array}$ & $\begin{array}{c}\mathrm{P}- \\
\text { VALUE }\end{array}$ \\
\hline Age, years; mean( $\pm \mathrm{SD})$ & $56.6(10.9)$ & $56.1(11.0)$ & 0.756 \\
Sex, women; $\mathrm{n}(\%)$ & $68(76.4)$ & $52(82.5)$ & 0.361 \\
Comorbidities & & & \\
BMI > 30 (obesity) n(\%) & $30(34.1)$ & $17(27.4)$ & 0.386 \\
BMI, mean( $\pm \mathrm{SD})$ & $28.2(5.0)$ & $27.2(5.0)$ & 0.205 \\
Dyslipemia, $\mathrm{n}(\%)$ & $20(22.7)$ & $11(18.6)$ & 0.552 \\
Hypertension, $\mathrm{n}(\%)$ & $23(25.5)$ & $16(25.8)$ & 0.996 \\
& & & \\
Insulin Resistance Indexes & & & \\
HOMA-IR>2,25, n(\%) & $25(28.7)$ & $17(27.9)$ & 0.908 \\
HOMA-IR, mean( $\pm \mathrm{SD})$ & $25(28.7)$ & $17(27.9)$ & 0.908 \\
HOMA- $\beta$, mean $( \pm \mathrm{SD})$ & $2.24(2.6)$ & $2.05(1.5)$ & 0.578 \\
QUICKI, mean( $\pm \mathrm{SD})$ & $46.7(32.3)$ & $45.1(32.1)$ & 0.848 \\
& & &
\end{tabular}

Conclusions: We did not find an increased IR in patients with RA compared with healthy controls, which may be due to adequate treatment and good control of inflammatory activity in the most of patients with RA. Obesity, diagnostic delay and inflammatory activity (measured by mean DAS28 index since the onset of the disease), were the predictors of IR in patients with RA in our study

\section{REFERENCES:}

[1] Clin Rheumatol 2016;35(1):43-53.

[2] Review. Front Immunol 2017;8:1745.

[3] Rev Bras Reumatol Engl Ed 2017;57(4):320-329.

[4] Biomed Res Int 2017:9670434.
Disclosure of Interest: S. Manrique-Arija Grant/research support from: Rheumatology Spanish Society, N. Mena-Vázquez: None declared, I. Ureña-Garnica: None declared, S. Abad-Sanchez: None declared, L. Ginel: None declared, C Fuego-Varela: None declared, M. Rojas-Gimenez: None declared, L. Cano-Garcia: None declared, F. Jimenez-Nuñez: None declared, G. Diaz-Cordoves: None declared, M. Ordoñez-Cañizares: None declared, C. Romero-Barco: None declared, R. Caparrós: None declared, M. Irigoyen: None declared, A. Fernandez-Nebro: None declared

DOI: 10.1136/annrheumdis-2018-eular.3868

\section{THU0176 THE EFFECT OF METHOTREXATE ON GASTROINTESTINAL SYMPTOMS IN PATIENTS WITH RHEUMATOID ARTHRITIS}

S. Asai ${ }^{1}$, K. Nagai ${ }^{2}$, T. Kojima ${ }^{1}$, N. Takahashi ${ }^{1}$, N. Ishiguro ${ }^{1}{ }^{1}$ Department of Orthopaedic Surgery, Nagoya University Graduate School of Medicine;

${ }^{2}$ Deparment of Nursing, Nagoya University Hospital, Nagoya, Japan

Background: Methotrexate (MTX) can cause gastrointestinal (GI) symptom in patients with rheumatoid arthritis (RA); however, it is uncertain how much dose of MTX affects GI symptoms. RA patients may receive various drugs besides MTX. NSAIDs are known to be a risk factor for GI disorders, and folic acid has been reported to reduce GI side effects of MTX. Moreover, obesity is a risk factor for reflux. Therefore, it is necessary to evaluate comprehensively the causes of $\mathrm{Gl}$ symptoms in RA patients.

Objectives: To compare prevalence of Gl symptoms for the patients with RA treated with low and high dose MTX, and investigate factors associated with GI symptoms.

Methods: A total of 529 patients with RA treated with MTX were included in this cross-sectional study. GI Symptom Rating Scale (GSRS) was used to evaluate GI symptoms. The GSRS has five subscales (Reflux, Abdominal pain, Indigestion, Diarrhoea and Constipation) and a seven-point graded Likert-type scale. Symptomatic was defined as a score of $>2$ on GSRS subscale. Patients were divided into two categories according to their MTX dosage: low dose ( $\leq 8 \mathrm{mg} / \mathrm{week}$ ) and high dose (>8 mg/week). Prevalence was compared by two groups with the chi-square test, and factors associated with Gl symptoms were assessed with multivariate logistic regression analysis.

Results: Patient characteristics are shown in table 1. Of all patients, $313(59 \%)$ received low dose MTX at a mean (SD) dose of $6.2(1.7) \mathrm{mg} /$ week, whereas 216 $(41 \%)$ received high dose MTX at a mean (SD) dose of $11.8(1.8) \mathrm{mg} /$ week. Relative to patients receiving low dose MTX, those receiving high dose MTX had a higher prevalence of reflux ( $24 \%$ vs $32 \%, p=0.047)$ and abdominal pain ( $18 \%$ vs $28 \%, p=0.008$ ) (figure 1). Multivariate analysis revealed that higher dose MTX was independently associated reflux (OR: $1.62,95 \% \mathrm{Cl}: 1.07-2.43$ ) and abdominal pain (OR: $1.70,95 \% \mathrm{Cl}: 1.12-2.59)$ (table 2). The odds ratio of reflux or abdominal pain in patients receiving high dose MTX was similar to that in patient receiving NSAIDs.

Abstract THU0176 - Table 1. Demographic and clinical characteristics of patients

\begin{tabular}{lccc}
\hline & $\begin{array}{c}\text { MTX } \leq 8 \mathrm{mg} / \mathrm{w} \\
(\mathrm{n}=313)\end{array}$ & $\begin{array}{c}\mathrm{MTX}>8 \mathrm{mg} / \mathrm{w} \\
(\mathrm{n}=216)\end{array}$ & $P$ value \\
\hline Age, years & $64 \pm 12$ & $60 \pm 15$ & $<0.001$ \\
Gender, female, $\mathrm{n}(\%)$ & $258(82)$ & $170(79)$ & 0.312 \\
Body mass index & $22 \pm 3$ & $22 \pm 3$ & 0.604 \\
Disease duration, years & $14 \pm 11$ & $11 \pm 9$ & $<0.001$ \\
MTX dose, mg/week & $6.2 \pm 1.7$ & $11.8 \pm 1.8$ & $<0.001$ \\
DAS28-CRP & $1.95 \pm 0.82$ & $2.24 \pm 0.99$ & $<0.001$ \\
Folic acid, n (\%) & $264(84)$ & $201(93)$ & 0.003 \\
csDMARD other than MTX, n & $32(10)$ & $50(23)$ & $<0.001$ \\
(\%) & & & \\
bDMARD, n (\%) & $108(35)$ & $44(20)$ & $<0.001$ \\
Glucocorticoid, n (\%) & $66(21)$ & $59(27)$ & 0.118 \\
NSAID, $\mathrm{n}(\%)$ & $95(30)$ & $84(39)$ & 0.050 \\
Proton pump inhibitor, $\mathrm{n}(\%)$ & $49(16)$ & $47(22)$ & 0.085 \\
\hline
\end{tabular}

Abstract THU0176 - Table 2. Factors associated with score of $>2$ on GSRS subscales

\begin{tabular}{lccc}
\hline Reflux & OR $(95 \% \mathrm{Cl})$ & Abdominal pain & OR $(95 \% \mathrm{Cl})$ \\
\hline Female & $1.94(1.11-3.39)$ & MTX $\leq 8 \mathrm{mg} /$ week (ref.) & 1.00 \\
NSAID & $1.71(1.13-2.68)$ & MTX $>8$ mg/week & $1.70(1.12-2.59)$ \\
MTX $\leq 8 \mathrm{mg} /$ week (ref.) & 1.00 & NSAID & $1.67(1.09-2.55)$ \\
MTX>8 mg/week & $1.62(1.07-2.43)$ & & \\
Body mass index* & $1.12(1.06-1.19)$ & & \\
Disease duration, year* & $1.02(1.01-1.04)$ & & \\
\hline
\end{tabular}

* Odds ratio for 1-unit increase in each item. 


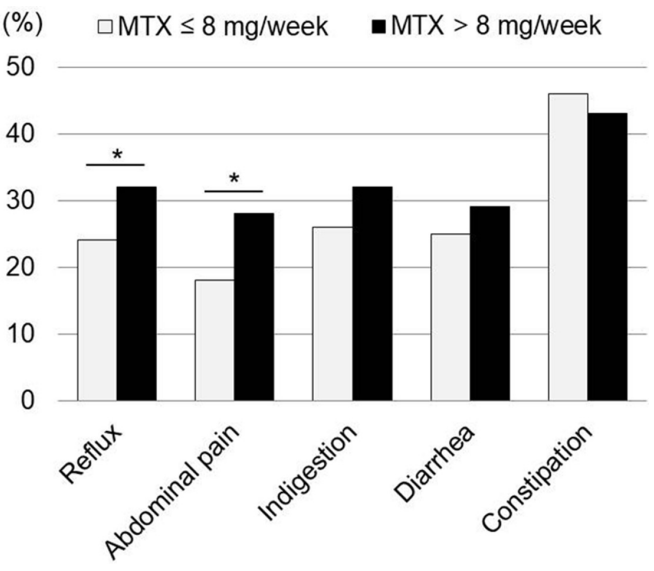

Abstract THU0176 - Figure 1. Percentage of patients with GSRS score $\geq 2$.

Conclusions: MTX more than $8 \mathrm{mg} /$ week is associated with upper Gl symptoms as much as NSAIDs in Japanese patients with RA.

Disclosure of Interest: None declared

DOI: 10.1136/annrheumdis-2018-eular.1715

\section{THU0177 CAN SIMPLE EDUCATIONAL FLASHCARDS CHANGE ATTITUDES TO VACCINATION IN AN UNDER- VACCINATED RHEUMATOID ARTHRITIS COHORT?}

S. Raghunath ${ }^{1,2}$, T. Kovitwanichkanont ${ }^{1,3}$, D. Wang $^{2}$, N. Walpola ${ }^{2}$, L. Kyi ${ }^{1}$, S. Pignataro ${ }^{1}$, S. Morton ${ }^{1}$, E. Thompson ${ }^{2}$, M. Leech ${ }^{1,2} .{ }^{1}$ Monash Health; ${ }^{2}$ Monash University, Melbourne; ${ }^{3}$ University of Sydney, Sydney, Australia

Background: There is increased infection risk in RA which relates to immune system dysregulation, comorbidities and immunosuppression. ${ }^{1,2}$ Therefore, there is a need to improve currently suboptimal vaccination rates reported globally. ${ }^{3}$ Objectives: To re-examine vaccination rates and to determine if educational flashcards with messages targeted to patient perceptions can change attitudes towards vaccination in a tertiary hospital RA clinic cohort.

Methods: Vaccination status and attitudes were examined in 126 consecutive rheumatoid arthritis clinic patients (data collection ongoing). Patients were then shown two simple educational flashcards and any shift in attitude to vaccination was recorded. Insights gleaned from a 2016 study on attitudes to vaccination in the same cohort were used to design the flashcards based on unvaccinated patients' main concerns. ${ }^{4}$

Results: The RA cohort was representative of a typical RA population. $67 \%$ of patients were female with a mean age of 57 years (range 18 to 88 years). $40 \%$ of patients were on biologic medication and $34 \%$ were on prednisolone. $13 \%$ of patients were previously hospitalised for influenza or pneumonia and $15 \%$ had a close contact hospitalised for these infections. $37 \%$ of patients had not received the influenza vaccine. In patients over 65 years old, $51 \%$ had not received the pneumococcal vaccine within the last 5 years, and of those, $80 \%$ had never been vaccinated against pneumococcal. Reasons reported for not being vaccinated included "I forget", "I worry about the side effects of vaccine", "I don't think I need the vaccine as I don't get the flu", and "I had the vaccine and it made me sick". $33 \%$ of patients were not aware of the hospitals free vaccination service, and of those that were aware of this service $13 \%$ cited this as their main reason for getting the vaccine.

After reading the education flashcards $49 \%$ of currently unvaccinated patients reported "I feel more informed and am more likely to get the vaccine next year". Rates of vaccination, infection and attitudes both pre and post flashcards did not differ between patients on biologics and not on biologics (all p-values $>0.05$ ).

\begin{tabular}{lc}
\hline \begin{tabular}{l} 
Reasons reported for not vaccinating (in order of frequency) \\
\hline 1
\end{tabular} & I forgot \\
\hline 2 & I am worried about the side effects of the vaccine. \\
3 & I don't think I need the vaccine as I don't get the flu. \\
4 & I don't think the vaccine will work., \\
5 & I have received it before so I don't need it or want it this \\
6 & year. \\
7 & I am afraid of needles \\
\hline
\end{tabular}

Vaccine Education Flashcards

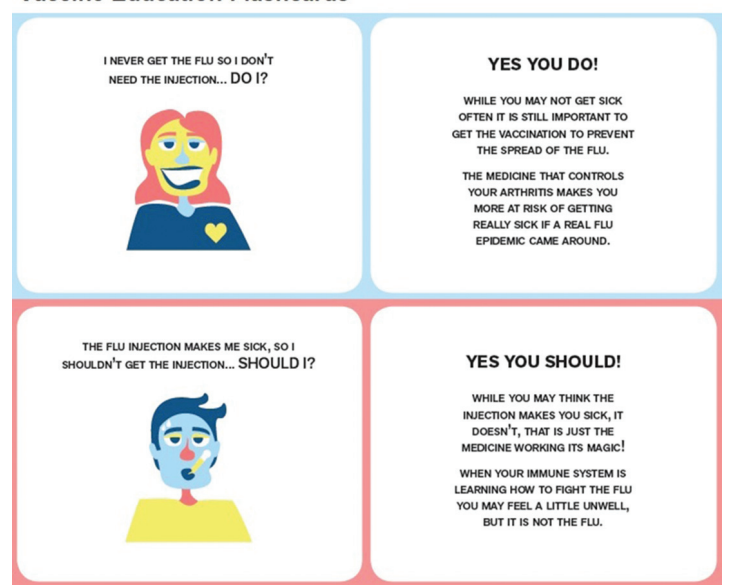

Conclusions: This at-risk RA cohort continues to be under-vaccinated in studies over the past two years. Simple flashcards showed potential to change attitudes in unvaccinated patients who were previously comfortable to express resistance. Insights from this study could be used to refine and reiterate this educational inter vention for implementation in a larger cohort to measure impact on vaccination rates in subsequent years.

\section{REFERENCES :}

[1] Doran M, et al. Arthritis \& Rheumatology 2002;46(9):2287-2293.

[2] Doran M, et al. Arthritis \& Rheumatology 2002;46(9):2294-2300.

[3] Hmamouchi I, et al. Vaccine 2015;33(12):1446-1452.

[4] Jh L, et al. Global Vaccines 2016;2.

Disclosure of Interest: None declared DOI: 10.1136/annrheumdis-2018-eular.4030

\section{THU0178 CLINICAL SIGNIFICANCE OF PERIODONTITIS IN RHEUMATOID ARTHRITIS PATIENTS: ASSOCIATION WITH DISEASE ACTIVITY, FUNCTIONAL STATUS AND RADIOLOGRAPHIC SCORE}

T.A. Gheita ${ }^{1}$, H.M. Fathi ${ }^{2}$, N. Khairy ${ }^{3}$, W.A. El-Battawy ${ }^{4} .{ }^{1}$ Rheumatology and Clinical Immunology, Faculty of Medicine, Kasr Al-Ainy School of Medicine, Cairo University, Cairo; ${ }^{2}$ Rheumatology, Faculty of Medicine, Fayoum University, Fayoum; ${ }^{3}$ Rheumatology, Faculty of Medicine, Cairo University; ${ }^{4}$ Oral Medicine and Periodontology, Faculty of Oral and Dental Medicine, Cairo University, Cairo, Egypt

\section{Background:}

Objectives: To evaluate frequency of periodontitis (PD) in rheumatoid arthritis (RA) patients and relate it with clinical characteristics, disease activity, functional status, anti-cyclic citrullinated peptide (anti-CCP) and radiographic scores.

Methods: The study included 60 RA patients and 30 controls. Clinical Disease activity index (CDAI), Modified Health Assessment Questionnaire (MHAQ), visual analogue scale of pain and Scott's modification to Larsen scoring method were assessed. Rheumatoid factor (RF) positivity and antiCCP titer were measured. Periodontal examination was performed and relevant indeces calculated

Results: The mean age of the patients was $49.1 \pm 13$ years and they were 52 females and 8 males. PD was present in $71.7 \%$ of RA patients versus $46.7 \%$ in control $(p=0.02)$. PD was predominantly generalised $(p=0.004)$ and moderatesevere degree $(p=0.01)$. Age $(p=0.007)$, disease duration $(p<0.0001)$, morning stiffness $(p=0.01)$, CDAI $(p<0.0001), \operatorname{MHAQ}(p=0.02)$, CRP $(p=0.02)$, anti-CCP titer $(p=0.01)$ and methotrexate treatment $(p=0.005)$ were significantly higher in RA-PD versus RA. However, gender, smoking, oral hygiene, erythrocyte sedimentation rate, $\mathrm{RF}$, anti-CCP positivity and radiographic scoring were insignificantly different. PD positivity was $96.3 \%$, predominant generalised in $92.6 \%$, moderate $(40.7 \%)$ and severe degree $(37 \%)$ in early RA versus $(51.5 \%, 24.2 \%, 24.2 \%, 12.1 \%$ respectively) in late RA patients. All PD indices were higher in early patients $(p \leq 0.05)$ while teeth loss $(p=0.03)$ was higher in late cases. CDAI, VAS and ACPA titer all signficantly correlated with PD indices $(p<0.05)$ Conclusions: Periodontitis is frequent in RA patients' especially in early cases and is remarkably associated to disease activity and reduced functional status.

Disclosure of Interest: None declared

DOI: 10.1136/annrheumdis-2018-eular.5201 